\title{
TOSCO E IMPERFECTO, CON MUCHO DE FABULADO: EL MAPA DE FRANCISCO DE SEYXAS Y LOVERA DE LA REGIÓN AUSTRAL MAGALLÁNICA
}

CLAYTON MCCARL

\section{RESUMEN}

Este artículo analiza el mapa de la Región Austral Magallánica que Francisco de Seyxas y Lovera (h.1646-h.1705) agregó a las "Taboas geraes da toda a navegacão", un atlas manuscrito de 1630 del cartógrafo portugués João Teixeira Albernaz I. Repaso brevemente la biografía de Seyxas hasta 1692, el año que le entregó el atlas al rey Carlos II en su Consejo de Indias, y la tradición cartográfica magallánica que existía en los años inmediatamente anteriores a la producción del mapa de Seyxas. Después, estudio en particular tres aspectos únicos de su mapa: las islas de Seyxas epónimas, el estrecho de La Roche y dos putativos asentamientos ingleses. Por último, propongo una lectura del mapa que nos permite entenderlo no solo como un capítulo curioso en la cartografía magallánica, sino también como reflejo de los discursos políticos, autobiográficos e imaginativos que caracterizan en un sentido amplio los escritos de Seyxas.

PALABRAS CLAVE: Francisco de Seyxas y Lovera, João Teixeira Albernaz I, cartografía, estrecho de Magallanes, estrecho de La Roche.

\section{TOSCO E IMPERFECTO, CON MUCHO DE FABULADO: FRANCISCO DE SEYXAS Y LOVERA'S MAP OF THE STRAIT OF MAGELLAN AND SURROUNDING AREA}

\begin{abstract}
This article analyzes the map of the Strait of Magellan and the surrounding area (the "Región Austral Magallánica") that Francisco de Seyxas y Lovera (c.1646-c.1705) added to the "Taboas geraes da toda a navegacão" (1630), a manuscript atlas by Portuguese cartographer João Teixeira Albernaz I. I review briefly the biography of Seyxas up to 1692, the year in which he remitted the atlas to Charles II in his Council of Indies, and the cartographic tradition related to the area in the years preceding the drawing of Seyxas's map. I then examine in particular three unique aspects of the map: the eponymous Islands of Seyxas, the Strait of La Roche, and two alleged English settlements. Lastly, I propose a reading that permits us to understand the map not only

a Associate professor of Spanish, University of North Florida. $₫$ clayton.mccarl@unf.edu
\end{abstract}


as an aberrant episode in the cartographic representation of the region, but also as a reflection of the political, autobiographical and imaginative discourses that characterize Seyxas's larger body of written work.

KEY WORDS: Francisco de Seyxas y Lovera, João Teixeira Albernaz I, cartography, Strait of Magellan, Strait of La Roche.

\section{INTRODUCCIÓN}

A principios de la década de 1690, el marinero y autor español Francisco de Seyxas y Lovera (h.1646-h.1705) llevó a cabo una serie de cambios en las "Taboas geraes da toda a navegacão" ${ }^{1}$ un atlas manuscrito de 1630 de João Teixeira Albernaz I, considerado el cartógrafo portugués más importante del siglo $\mathrm{XVII}^{2}$. Seyxas añadió un texto introductorio, impuso títulos en castellano, anotó el mapa del área que rodea el estrecho de Magallanes e introdujo otra representación propia de esa misma región (Fig. 1). Varios autores han escrito sobre las "Taboas geraes", notando aquellas modificaciones como parte de la historia del atlas ${ }^{3}$, que reside desde 1922 entre los fondos de la Library of Congress en Washington, D.C. ${ }^{4}$

En un reciente artículo ${ }^{5}$, considero los problemas de autoría a que nos enfrentamos a la hora de interactuar con el atlas. En aquel trabajo, analizo las "Taboas geraes" como un artefacto único cuyo sentido Seyxas alteró de forma permanente con sus intervenciones. Examino

1 Teixeira Albernaz I, 1630. Taboas geraes da toda a navegaçã divididas e emendadas por Dom Ieronimo de Attayde com todos os portos principaes das conquistas de Portugal. Delineadas por Ioão Teixeira Cosmographo de Sua Magestade. Anno de 1630. Library of Congress, Geography and Map Division, Washington. https://www. loc.gov/resource/g3200m.gct00052.

2 Bagrow, 1964. History of Cartography. Harvard University Press, Cambridge, n.p.; Cortesão y Teixeira da Mota, 1960. Portugaliae monumenta cartographica. Comemorações do V Centenário da Morte do Infante D. Henrique, Lisboa, Tomo 4, pp. 79-86; Putnam, 1985. Early maps and charts of the West Coast of North America: On the history of maps and sea charts, cartographers and publishers and on some periods of American history. Mercbook International, Guernsey, p. 19; Romero Magalhães et al. (Coords.), 1997. Tesouros da cartografia portuguesa. Ediciões Inapa, Lisboa, pp. 59-62.

3 Fernández de Navarrete, 1846. Disertación sobre la historia de la náutica y de las ciencias matemáticas. Imprenta de la viuda de Calero, Madrid, p. 402; Martinic, 1997. Rarezas las acciones de Seyxas no solo como accidentes casuales en la trayectoria del atlas, sino como actos retóricos que merecen estudiarse por su propia cuenta.

El presente artículo continúa ese análisis al considerar más detalladamente uno de los cambios que realizó Seyxas en el atlas: la inserción de su propio mapa de la Región Austral Magallánica. Primero repaso brevemente la biografía del autor hasta 1692 -un año determinante en la historia de su mediación del atlas- además de la tradición cartográfica magallánica que existía en las décadas anteriores a la producción del mapa de Seyxas. Después, estudio en particular tres aspectos únicos de su representación: las islas de Seyxas epónimas, el estrecho de La Roche y dos putativos asentamientos ingleses. Por último, propongo una lectura del mapa que nos permite aproximarnos a él no solo en términos de las verdades geográficas e históricas -o la distorsión de ellas-, sino también en el contexto de los discursos políticos, autobiográficos e imaginativos que caracterizan los escritos de Seyxas, tanto sus libros impresos como los que permanecen inéditos.

cartográficas. I. Las cuatro versiones del mapa de Chile del padre Alonso de Ovalle. II. El curioso mapa de la región magallánica de Francisco de Seixas y Lovera (1690). Boletín de la Academia Chilena de la Historia, 107, 385-400; Martinic, 1999. Cartografía magallánica 1523-1945. Ediciones de la Universidad de Magallanes, Punta Arenas, p. 104; Martinic, 2005. De la Trapananda al Áysen: una mirada reflexiva sobre el acontecer de la Región de Aysén desde la prehistoria hasta nuestros días. Pehuén, Santiago, p. 59; Reitano, 2008. Carta de Francisco de Seyxas y Lovera en el Atlas Hidrográfico de João Teixeira de 1630. Anuario del Instituto de Historia Argentina, 8, 209-212.

4 Library of Congress, 1922. Report of the Librarian of Congress [...] for the fiscal year ending June 20, 1922. Government Printing Office, Washington, p. 68; Maggs Bros, 1921. The voyages and discoveries of early travellers and missionaries. Part I. America, Maggs Bros, London, pp. 46-51.

5 McCarl, 2018b. The 'Taboas geraes' of João Teixeira Albernaz I as a mediated textual object. Quaerendo, 48(2), 106-126. 


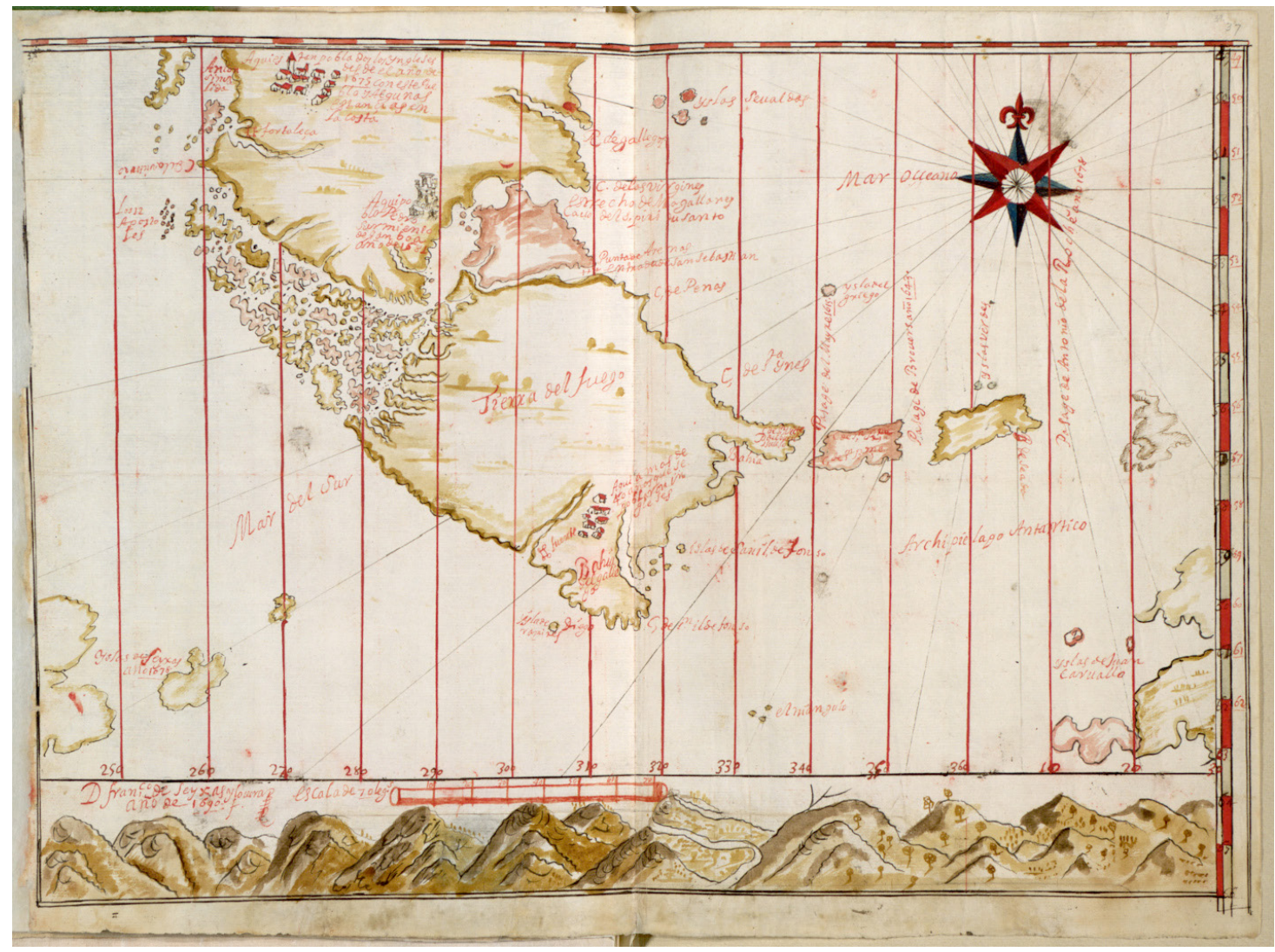

Fig. 1. Mapa de Seyxas y Lovera, 1690, de la Región Austral Magallánica. Library of Congress, Geography and Map Division, Washington, D.C.

FRANCISCO DE SEYXAS Y LOVERA Y SU PREOCUPACIÓN POR LA REGIÓN MAGALLÁNICA

Seyxas es una figura singular en las letras hispánicas del siglo XVII. Según relata en el prólogo al Theatro real del comerzio de las monedas ${ }^{6}$, un texto manuscrito que se encuentra en la Real Biblioteca (Madrid), el autor quedó huérfano de niño en su Galicia natal, recibió una corta escolarización en Salamanca de adolescente, y luego fue trasladado por familiares a Sanlúcar de Barrameda alrededor de 1656. Aparentemente esperando que aprendiera francés y se convirtiera

6 Seyxas y Lovera, 1688b. Theatro real del comerzio de las monedas de la monarchia del Rey nuestro señor, con la mayor parte de todos los ymperios, reynos, y prouincias, de toda la mayor parte del universo, en que se manifiestan los considerables intereses que se llevan las naçiones por la falta de estimacion que las monedas esta en representante de sus intereses comerciales, su familia lo envió entonces a Saint-Malo. Seyxas pronto abandonó el puesto que le habían conseguido, partiendo de Francia para la India en un viaje en que circunnavegó el globo, a pesar de varias peripecias y contratiempos. De vuelta a Europa, formó una compañía de comercio con socios holandeses, ingleses y portugueses, que juntos emprendieron una expedición exitosa al Oriente. Como parte de las ganancias, a Seyxas le correspondió un navío, el cual capitaneó durante casi tres décadas, haciendo numerosos viajes comerciales entre Europa, Asia, África y América. Sirvió además como capitán de corso, empleando

monarcha deven tener. Real Biblioteca, Madrid, II/1800 [tratado manuscrito; el prólogo se transcribe en Seyxas y Lovera, 2011. Piratas y contrabandistas de ambas Indias, y estado presente de ellas (1693). McCarl (Ed.), Fundación Pedro Barrié de la Maza, La Coruña, pp. 213-225]. 
su nave contra buques extranjeros en diferentes momentos, provisionado de comisiones reales que legitimaban tales actividades ${ }^{7}$.

A mediados de la década de 1680 Seyxas se enfrentaba a acusaciones de contrabando, de incumplimiento de obligaciones financieras y de ser secretamente un agente extranjero. Dejando su barco al mando de un asociado, se instaló en Madrid, donde se dedicó a limpiar su nombre. Aprovechando sus experiencias marítimas, comenzó a escribir, y en 1688 imprimió su primer libro, Theatro naval hidrographico, un tratado sobre las mareas y corrientes oceánicas. Dos años después, Seyxas publicó su segundo libro, Descripcion geographica y derrotero de la region austral magallanica, un estudio científico y ensayo sobre la urgencia de establecer el control sobre aquella ruta 8 .

En 1692, Seyxas adquirió un puesto en la burocracia colonial, como alcalde mayor de Tacuba, una villa fuera de la ciudad de México9. Posiblemente como parte de lo que sería la correspondiente transacción monetaria ${ }^{10}$, el autor le entregó a la Corona las "Taboas geraes". Según Seyxas, había procurado el atlas en 1681, hurtándolo de la Biblioteca Real de Lisboa, a través de conexiones personales y la remisión de fondos ${ }^{11}$. Es posible que hubiera querido conseguir el atlas para utilizarlo en la navegación, y en tal caso tendría sentido que estuviera dispuesto a deshacerse de él a la hora de comenzar su nueva carrera burocrática. En cualquier caso, antes de presentárselo al rey en su Consejo de Indias, Seyxas efectuó los cambios que hemos enumerado.

7 McCarl, 2011. Introducción. Seyxas y Lovera, F. Piratas y contrabandistas de ambas Indias, y estado presente de ellas (1693). La Coruña: Fundación Pedro Barrié de la Maza, p. xii-xxii.

8 Ibidem, p. xii, pp. xxii-xxviii; Seyxas y Lovera, 1688a. Theatro naval hidrographico de los fluxos, y refluxos, y de las corrientes de los mares, estrechos, archipielagos, y passages aquales del mundo. Antonio de Zafra, Madrid; 1690. Descripcion geographica, y derrotero de la region austral magallanica. Antonio de Zafra, Madrid. Reproduzco los datos bibliográficos de los textos impresos antes del siglo XX tal como aparecen en el original, regularizando únicamente el uso de las letras minúsculas y mayúsculas. De la misma forma, no modernizo cuando cito de forma textual de aquellos libros u otros textos impresos o manuscritos que datan de los siglos anteriores al XX.

9 McCarl, 2011, op. cit., p. xxvii.
La creación del mapa que examinamos aquí responde en parte a la preocupación que Seyxas sentía por la seguridad de la región magallánica. En un principio, el mapa estaba destinado a figurar en Descripcion geographica, que Seyxas había publicado dos años antes. Sin embargo, según el autor, el Consejo de Indias impidió su inclusión por motivos de seguridad. Seyxas explica estas circunstancias en una nota marginal a otro mapa de la misma región que preparó en 1703 en Versailles (Fig. 2), donde pasó sus últimos años ${ }^{12}$. A propósito de Descripcion geographica, Seyxas afirma en aquella nota que nò expresó en el la mitad de lo que devió decir, ni tan poco puso el presente Mapa, porque dicho Consejo no se lo permitió.

Aquel mapa posterior, que se encuentra en el Centre des Archives diplomatiques de La Courneuve en Francia, acompaña un tratado en que Seyxas considera otra vez, entre otros asuntos, la geografía y defensa del estrecho de Magallanes y el área que lo rodea ${ }^{13}$. Aquella obra se titula "Libro quarto del virreynato del Tocuman"14, y es parte de la serie inédita "La verdadera unión de las dos coronas de España y Francia"15. Mientras varios de los capítulos (que Seyxas denomina discursos) examinan la región magallánica, el séptimo se dedica específicamente a la explicación del mapa. En el resumen que figura en la tabla de contenidos, Seyxas explica que aquel discurso:

$[.$.$] hace descripcion geographica$
demostrando en relacion todo lo
contenido que se demuestra en el

10 McCarl, 2014a. Introducción. Seyxas y Lovera, F. Avisos a pretendientes para Indias. En Scholarly Editing: The Annual of the Association for Documentary Editing, 35 n. 29. http://scholarlyediting.org/2014/editions/intro. avisos.html.

11 Seyxas y Lovera, 2011, op. cit., pp. xiii-xiv; McCarl, 2018b, op. cit, pp. 109-110.

12 Seyxas y Lovera, 1703b, Mapa manuscrito de la región magallánica, Centre des Archives diplomatiques de La Courneuve, France, Mem. et Doc. 122 (Esp. 129), fol. $183 r$.

13 Seyxas y Lovera, 1703a, "Libro quarto del virreynato del Tocuman", Centre des Archives diplomatiques de La Courneuve, France, Mem. et Doc. 122 (Esp. 129), fols. 3r-183r.

14 Ibidem, fol. 6r.

15 McCarl, 2011, op. cit., p. xvi, n. 14. 


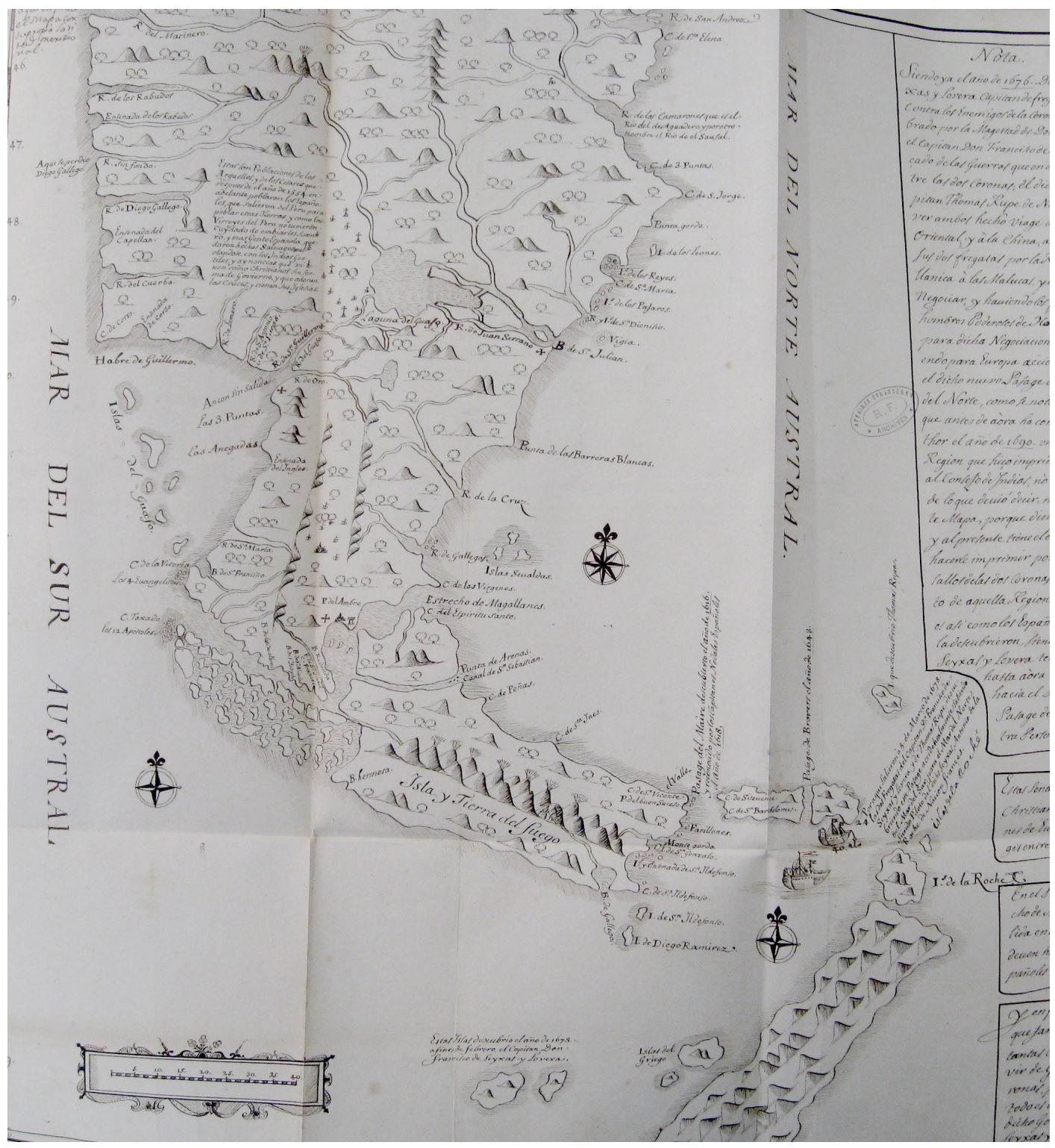

Fig. 2. Mapa de Seyxas y Lovera, 1703, de la Región Austral Magallánica.

FR-MAE Centre des Archives diplomatiques de La Courneuve, Francia.

presente mapa de la Region Austral Magallanica, trantandose especialmente de todas las sus tierras y habitantes, y de sus puertos, y costas de ambos mares del Norte, y del sur, y del Estrecho de Magallanes, y de los pasages del mayre de Brovers, y del de Seyxas y Rupe manifestando que toda esta region se compone de un archipielago de yslas compuestas muchos pasages del Mar del Norte al Mar del Sur ${ }^{16}$.

Al final de la tabla de contenidos, Seyxas anuncia la presencia del mapa como el último elemento en el volumen: Siguese el mapa de la Region Austral Magallanica ${ }^{17}$. 
Como queda claro por la Cartografía magallánica 1523-1945 de Mateo Martinic ${ }^{18}$, otros habían desarrollado mapas del área en los años anteriores a los esfuerzos de Seyxas. Uno de Guillaume Sanson, $1668^{19}$, y otro por un autor anónimo inglés, $1671^{20}$, muestran todo el continente al sur del río de la Plata. La expedición de John Narborough a Chile en los años 16691671 produjo varias cartas náuticas, incluyendo una que se imprimió en Londres con el nombre del cartógrafo John Thornton ${ }^{21}$ y otras dos anónimas de $1670^{22}$ que quedaron inéditas, todas representando únicamente el Estrecho. Un mapa de Arnoldus Montanus y John Ogilby, $1671^{23}$, es quizás otro producto de aquel viaje. Frederik de Witt, $1675^{24}$, Antonio de Vea, $1676^{25}$ y Alain Manneson Mallet, $1683^{26}$ produjeron otros mapas. Martinic también recoge dos mapas anónimos españoles ${ }^{27}$ que datan del mismo año en que Seyxas dibujó su propia representación de la región.

\section{TRES ASPECTOS SINGULARES}

El mapa de Seyxas se distancia de todas las mencionadas cartas en por lo menos tres rasgos: las islas de Seyxas, el estrecho de La Roche y las dos colonias inglesas. El primero tal vez no sea sino una curiosidad sin mayor trascendencia fuera de la biografía del autor. El segundo, en cambio, tiene largas repercusiones en la cartografía de la región, y ambos el segundo y el tercero implican

18 Martinic, 1999, op. cit., pp. 101-104.

19 Sanson, 1668, La Terre et les Isles Magellaniques, reproducido en Martinic, 1999, op. cit., p. 57.

20 Anónimo, 1671, Tabla del procedimiento del viaje de una fragata y un patache inglés al estrecho de Magallanes, reproducido en Martinic, 1999, op. cit., p. 60.

21 Thornton et al., h. 1670, A New Mapp of Magellan's Straights: Discovered by Capt. John Narbrough (Com $[\mathrm{m}]$ ander Then of His Majesty's Ship the Sweepstakes) As He Sayled Through the Sade Straights. London. JCB Map Collection, John Carter Brown Library. https://jcb. lunaimaging.com/luna/servlet/s/syjlwm.

22 Anónimo, 1670a, "A mapp of the streights of Magelan", British Library. Add. MS. 5414, artículo 29, reproducido en Martinic, 1999, op. cit, p. 59; Anónimo, 1670b, "The Land of Patagonia [etc.]", British Library, Maps K. Top. 124.84, reproducido en Narbrough, 2018, The voyage of Captain John Narbrough to the Strait of Magellan and the South Sea in His Majesty's ship Sweepstakes 1669-1671. Editado por R.J. Campbell, P.T. Bradley y J. Lorimer. London: Routledge. Works Issued by the problemas historiográficos que quedan sin resolver.

\section{Las islas de Seyxas}

Al suroeste de la Tierra del Fuego, el autor se inscribe en la cartografía de la región, dibujando las islas de Seyxas (Fig. 3) y señalando 1678 como el año de su descubrimiento. La presencia de las islas en el mapa no tiene correspondencia en sus libros contemporáneos, pues no las menciona ni en Descripcion geographica ni tampoco en Piratas y contrabandistas de ambas Indias, y estado presente de ellas, un tratado de 1693 que se publicó por primera vez en $2011^{28}$. En su mapa posterior de la misma región ${ }^{29}$, Seyxas otra vez representa el archipiélago, reiterando el rol que él tuvo en su descubrimiento, y apuntando la misma fecha: Estas Islas descubrio el año de 1678. a fines de febrero, el Capitan Don Francisco de Seyxas y Lovera (Fig. 4).

Hasta ahora, no disponemos de ningún dato más sobre el asunto. Martinic propone la posibilidad de que Seyxas se refiera a las islas Shetland del Sur, y que su mapa así presente la primera representación cartográfica conocida de aquel archipiélago antártico ${ }^{30}$. Cualquiera que sea el caso, la innovación de Seyxas no se integró a la tradición cartográfica de la región, y las denominadas islas de Seyxas solo parecen figurar en los dos mencionados mapas del mismo autor.

Hakluyt Society Third Series $N^{\circ} 33$, insertado entre pp. 368 y 369.

23 Montanus y Ogilby, 1671, Tabula magellanica, reproducido en Martinic, 1999, op. cit., p. 61.

24 Witt, 1675, Tractus Australior Americae Meridionalis, reproducido en Martinic, 1999, op. cit., p. 61.

25 Vea, 1676, Exploración de las costas del extremo sur del continente, reproducido en Martinic, 1999, op. cit., p. 62.

26 Manneson, 1683, Detroit de Magellan, reproducido en Martinic, 1999, op. cit., p. 63.

27 Anónimo, 1690a, "Mapa del estrecho de Magallanes y del nuevo de Mayre", Museo Naval, Madrid, reproducido en Martinic, 1999, op. cit., p. 65; Anónimo, 1690b, "Mapa del estrecho de Magallanes y del nuevo de Mayre", reproducido en Martinic, 1999, op. cit., p. 66.

28 Seyxas y Lovera, 2011, op. cit.

29 Seyxas y Lovera, 1703b, op. cit.

30 Martinic, 2002. La curiosa primera representación de islas antárticas en un mapa del siglo XVII. En VI Encuentro de Historiadores Antárticos Iberoamericanos, Instituto Antártico Chileno, pp. 57-62. 


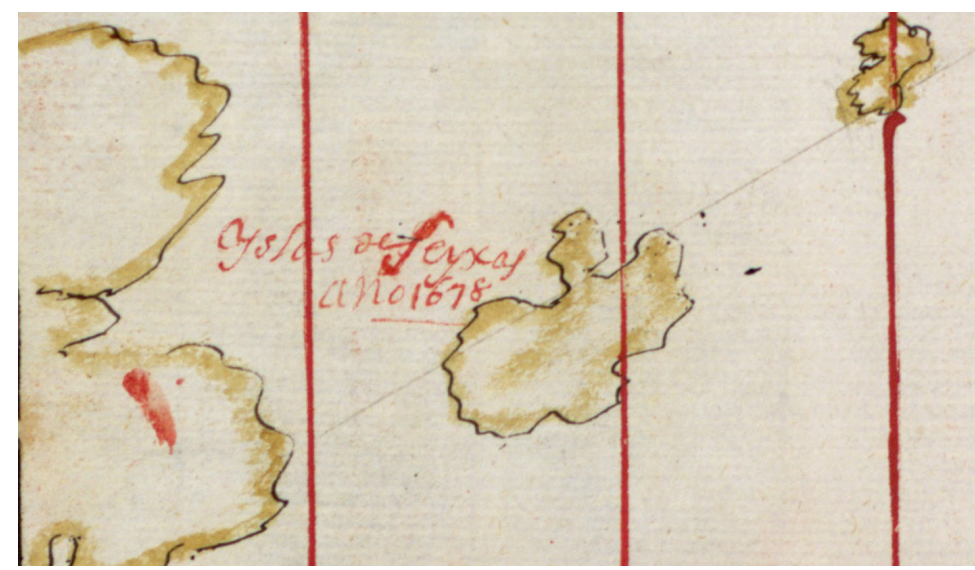

Fig. 3. Detalle del mapa de Seyxas y Lovera, 1690: las "Yslas de Seyxas". Library of Congress, Geography and Map Division, Washington, D.C.

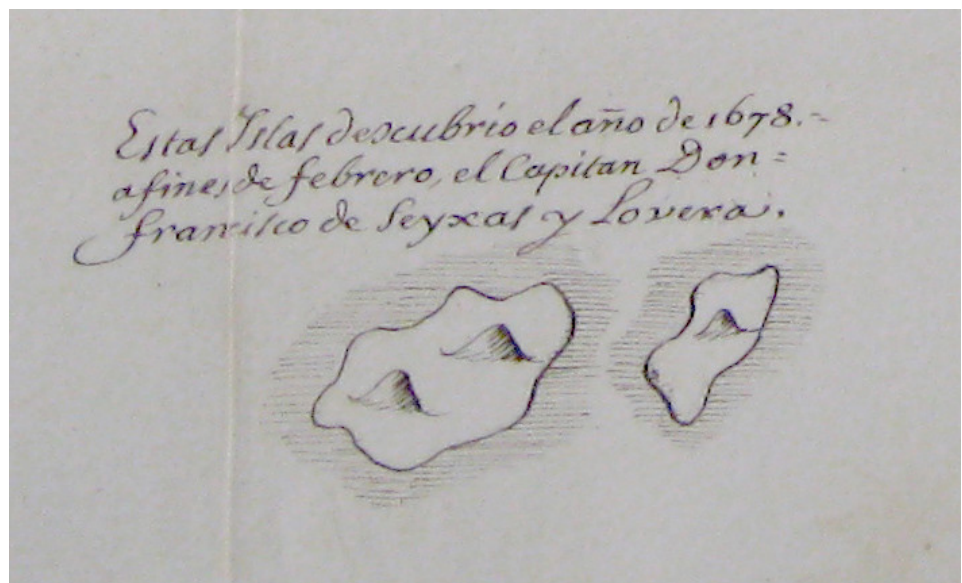

Fig. 4. Detalle del mapa de Seyxas y Lovera, 1703: las "Yslas de Seyxas". FR-MAE Centre des Archives diplomatiques de La Courneuve, Francia.

El estrecho de La Roche

Otra de las características más notables del mapa de Seyxas es el estrecho de La Roche (Fig. 5). Es el tercero de los tres pasajes que el autor representa al este de la Tierra del Fuego. El primero de aquellos es el estrecho de Le Maire, que Jacob Le Maire y Willem Corneliszoon Schouten descubrieron en 1616 al pasar entre la isla Grande de Tierra del Fuego y la tierra que denominaron Stateneiland -la actual isla de los Estados-. El descubrimiento de Le Maire y Schouten marcó un hito en la historia de las navegaciones europeas al Mar del Sur, y la alarma

31 Bradley, 1989. The lure of Peru: maritime intrusion into the South Sea, 1598-1701. St. Martin's Press, New York, que provocó en Madrid motivó la expedición de Bartolomé García Nodal y Gonzalo de Nodal, que comprobaron la información de los holandeses ${ }^{31}$. El estrecho de Le Maire empezó a representarse en los mapas poco después del viaje de Le Maire y Schouten, y el pasaje sigue llamándose así en la actualidad.

El segundo estrecho es el pasaje de Brouwer (pasaje de Brovers en el mapa de Seyxas) que el holandés Hendrick Brouwer afirma haber descubierto en un viaje a Chile en 1643. En su diario, Brouwer explica que, acercándose al estrecho de Le Maire, percibió que la Tierra de los Estados no formaba parte de la legendaria Tierra

pp. 50-51. 


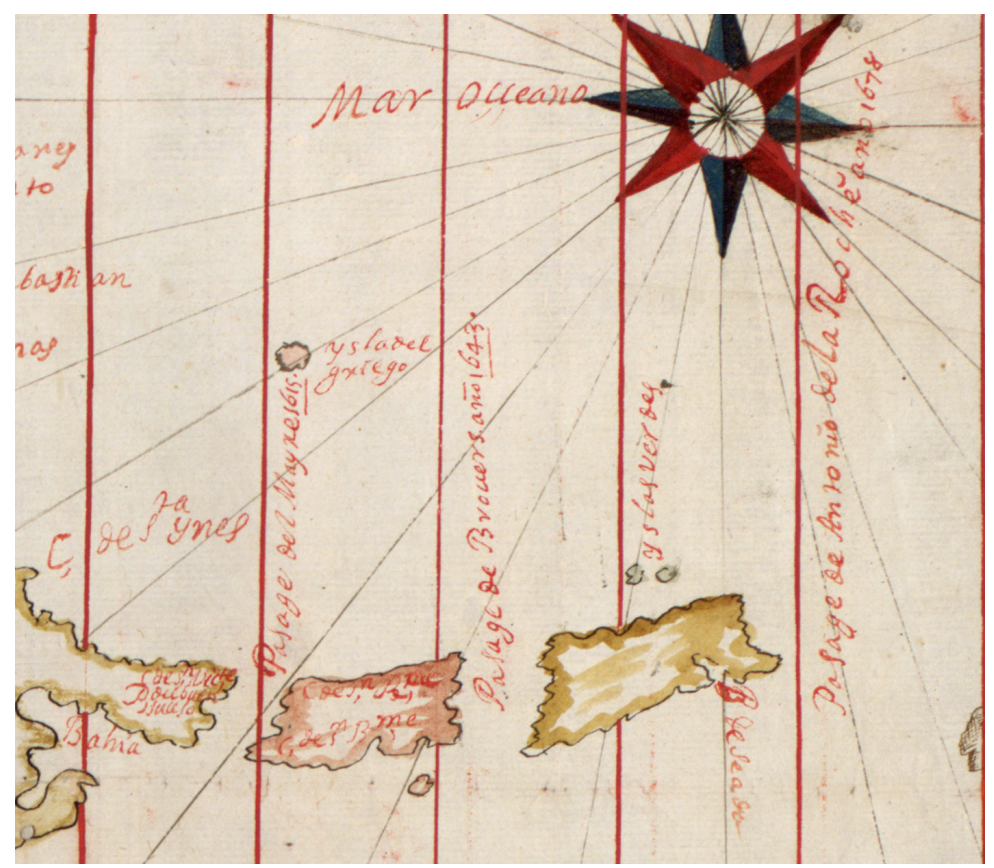

Fig. 5. Detalle del mapa de Seyxas y Lovera, 1690:

los estrechos de Le Maire, de Brouwer and de La Roche.

Library of Congress, Geography and Map Division, Washington, D.C.

Austral, sino que era isla. Al no poder entrar al estrecho de Le Maire por las inclemencias del tiempo, Brouwer decidió navegar alrededor de aquella isla, y así descubrió una nueva ruta al Mar del Sur ${ }^{32}$. En Descripcion geographica y en Piratas y contrabandistas, Seyxas narra el descubrimiento de forma diferente, indicando que sucedió mientras Brouwer pasaba del Mar del Sur al Mar del Norte, citando en Descripcion geographica tres versiones diferentes del diario de la expedición ${ }^{33}$. De todas formas, estrecho de Brouwer, Brouwers passage y otras etiquetas análogas aparecían al este de la

32 Seelstrang, 1885. Apuntes históricos sobre la Patagonia y la Tierra del Fuego. XX[.] Brouwer. Boletín del Instituto Geográfico Argentino, 6, pp. 77-81; Medina, 1926. Relación del viaje de Hendrick Brouwer a Valdivia en 1643. En Opúsculos varios de J. T. Medina. Tomo 3, Feliú Cruz (Ed.), Imprenta Universitaria, Santiago, pp. 84-86.

33 Seyxas y Lovera, 1690, op. cit., fol. 25v-27r; 2011, op. cit., pp. 137-138.

34 Por ejemplo, registran el estrecho los mapas de Pruth, 1656, Le Paraguayr, le Chili, la Terre, et les Isles Magellanicques, Chez Pierre Mariette, rue Sainct Iacque à l'Esperance, Paris, JCB Map Collection, John Carter Brown Library, https://jcb.lunaimaging.com/ luna/servlet/s/nc58qh; Janssonius, h. 1659, Tabula isla de los Estados en algunos mapas hasta por lo menos fines del XVIII ${ }^{34}$.

La posterior desaparición del Estrecho de los mapas se debe seguramente al hecho de que, en realidad, se trataba de mar abierto, no un pasaje entre dos tierras definidas. Por ejemplo, Giovanni Coleti ${ }^{35}$ registra el paso en su Dizionario storicogeografico solo para negar su existencia, notando que es un [e]strecho que en 1643 algunos Ingleses creyeron haber encontrado hacia los $55 \mathrm{gr}$. de Lat. Sur, al Sureste del Estrecho de Maire. Como explica Coleti, no se trataba de una verdadera

magellanica qua Tierrae del Fuego cum celeberrimis fretis a F. Magellano et I. Le Maire detectus novissima et accuratissima descriptio exhibetur, Apud Joannem Janssonium, Amsterdam. JCB Map Collection, John Carter Brown Library, https://jcb.lunaimaging.com/ luna/servlet/s/noyfw8; Sanson, 1680, South America divided into its principall parts, Sold by William Berry, London, JCB Map Collection, John Carter Brown Library, https://jcb.lunaimaging.com/luna/servlet/s/ x01n31; Jaillot, 1696, L'Amerique meridionale divisée en ses principales parties, Chez $\mathrm{H}$. Jaillot, Paris, JCB Map Collection, John Carter Brown Library, https://jcb. lunaimaging.com/luna/servlet/s/9hyjpj; L'Isle, 1716, Carte du Paraguay, du Chili, du Detroit de Magellan 
posibilidad geográfica: [e]n realidad no podía existir, puesto que no hay tierra alguna hacia el Sur, y por lo tanto, no debe ser considerado como estrecho. Unos años después, Antonio de Alcedo $^{36}$ reproduce la misma información de Coleti en su Diccionario geográfico-histórico de las Indias Occidentales, repitiendo incluso la aparente equivocación sobre la nacionalidad de Brouwer y su tripulación.

Aunque el descubrimiento de un estrecho de Brouwer se interprete como malentendido o error de percepción, el viaje de Brouwer en sí se acepta como un hecho histórico, tanto como el de Le Maire y de Schouten. El caso del viaje de Antonio de la Roche es distinto, pues la expedición, el estrecho, e incluso la misma persona de La Roche posiblemente sean innovaciones de Seyxas, de cuyos textos proceden todos los datos conocidos. El autor cuenta el descubrimiento del pasaje primero en Descripcion geographica, y tres años más tarde, en Piratas y contrabandistas.

Según Seyxas, La Roche era un comerciante inglés de ascendencia francesa. En Descripcion geographica lo clasifica de la

\&c., Chez la veuve de Paul Marret, A Amsterdam, JCB Map Collection, John Carter Brown Library, https:// jcb.lunaimaging.com/luna/servlet/s/t62xm0; L'Isle, h. 1759, Typus Geographicus Chili Paraguay Freti Magellanici \&c., Per Homanianos Heredes, Nuremberg, JCB Map Collection, John Carter Brown Library, https://jcb.lunaimaging.com/luna/servlet/s/hr7j4t; Moll, 1720, Map of South America including part of Central America, Solomon Islands, and a small part of Africa, Printed for H. Moll, London, JCB Map Collection, John Carter Brown Library, https://jcb.lunaimaging. com/luna/servlet/s/ruola4; Moll, h. 1736, A map of Chili, Patagonia, La Plata and ye south part of Brasil, T. Bowles, London, David Rumsey Map Collection, https://www.davidrumsey.com/luna/servlet/detail/ RUMSEY 8 1 3769 430105?id=1-1-3769-430105; Senex, h. 1755, South America corrected from the observation communicated to the Royal Society's [sic] of London \& Paris, Printed for T. Bowles, London, JCB Map Collection, John Carter Brown Library, https://jcb. lunaimaging.com/luna/servlet/s/54mghp; Delarochette, h. 1771, South America from the latest discoveries, shewing the Spanish \& Portuguese settlements according to Mr. D'Anville by De Larochette, Printed for John Bowles, London, JCB Map Collection, John Carter Brown Library, https://jcb.lunaimaging.com/ luna/servlet/s/7c072z; D' Anville, 1772, A map of the whole continent of America divided into North and South and West Indies, Robt. Sayer, London, JCB siguiente forma: Mercader Inglès (aunque hijo de padre Francès, y nacido en Lo[n]dres). En Piratas y contrabandistas, omite la mención del linaje gálico de La Roche, llamándolo inglés y mercader que vivía en Cádiz. Como cuenta Seyxas, La Roche emprendió con sus asociados una expedición comercial infructuosa a la costa pacífica de América del Sur en los años 167475. El autor relata que, al intentar su regreso del Pacífico al Atlántico en el año 1675, La Roche no pudo entrar al estrecho de Le Maire ni al de Brouwer, por el mal tiempo. Más allá del de Brouwer, sin embargo, descubrió otro pasaje -que después llevaría su nombre- al norte de una tierra alta y cubierta de nieve ${ }^{37}$.

En Piratas y contrabandistas, Seyxas no explica cuál es la fuente de la historia que narra, pero en Descripcion geografica parece trabajar a partir de por lo menos una fuente escrita. Se trata de una descripción que, según el mencionado autor, La Roche publicó de forma clandestina en 1678 en Londres, escrita en francés, impresa en 12 pliegos y encuadernada en cuarto ${ }^{38}$. Asimismo, Seyxas cita un derrotero de La Roche ${ }^{39}$, que

Map Collection, John Carter Brown Library, https:// jcb.lunaimaging.com/luna/servlet/s/5vi83h; Liebaux le fils, 1780, Carte du Paraguay du Chili du detroit de Magllan \&c., Chez Dezauche Successeur des Srs. De l'Isle et Buache, Paris, JCB Map Collection, John Carter Brown Library, https://jcb.lunaimaging.com/ luna/servlet/s/27aez2; Kitchin, 1784, A new map of the whole continent of America divided into North and South and West Indies, Printed for Robt. Sayer and John Bennett, London, JCB Map Collection, John Carter Brown Library, https://jcb.lunaimaging.com/ luna/servlet/s/nbqc9d; Cano y Olmedilla, 1799, Mapa geográfico de América meridional, Guillermo Faden, London, JCB Map Collection, John Carter Brown Library, https://jcb.lunaimaging.com/luna/servlet/s/ cl5fqc.

35 Coleti, 1975 [1771]. Diccionario histórico-geográfico de la América Meridional. Banco de la República, Bogotá, Tomo 1, p. 80; Coleti, 1771. Dizionario storicogeografico dell'America meridionale. Nella Stamperia Coleti, Venezia, Tomo 1, p. 51.

36 Alcedo, 1788. Diccionario geográfico-histórico de las Indias Occidentales. Imprenta de Manuel González, Madrid, Tomo 1, p. 276.

37 Seyxas y Lovera, 1690, op. cit., fol. 27v-30v; 2011, op. cit., pp. 153-154.

38 Seyxas y Lovera, 1690, op. cit, fol. 27v.

39 Ibidem, fol. 29r, 47r. 
también menciona en la primera edición de Theatro naval hidrographico ${ }^{40}$. Es posible que la descripción y el derrotero sean el mismo texto, pues hay precedente incluso en el título del tratado del propio Seyxas, que emplea los dos términos: Descripcion geographica, y derrotero de la region austral magallanica (énfasis mío). En cualquier caso, no se conoce ningún texto que pueda ser ni la descripción ni el derrotero ni una combinación de los dos. Como es el caso con varias de las otras putativas fuentes escritas que el autor cita en Piratas y contrabandistas, no queda rastro en los registros bibliográficos del texto -o de los textos- de La Roche ${ }^{41}$.

La dificultad de evaluar la posible veracidad de lo que narra Seyxas se vuelve mayor por la forma en que cuenta la misma historia desde Versailles en el mapa posterior ${ }^{42}$. En aquel documento, Seyxas afirma haber descubierto el pasaje él mismo, como parte de un viaje que hizo junto a otro comerciante, que identifica como Thomas Rupe. En ese mapa, la fecha del descubrimiento no es 1675 , como en Descripcion geographica y Piratas y contrabandistas, sino 1678, el mismo año en que el autor descubrió supuestamente las islas de Seyxas.

En el mapa de 1703, Seyxas también ofrece datos distintos sobre la identidad de La Roche. A diferencia de lo que indicó en sus textos anteriores, en aquel documento señala que La Roche no fue capitán sino piloto, y que no era inglés, sino francés. Como anota en el mapa a propósito del Estrecho: Por aqui Salieron à 8. de Março de 1678. las dos Fregatas del Capitan D[o]n Francisco de Seyxas y Lovera, y de Thomas Rupe descubriendo este Pasage accidentalmente saliendo del Mar del Sur, para el Mar del Norte Siendo Piloto del dicho Seyxas, Antonio de la Roche de Nacion françes ${ }^{43}$.

En una nota marginal Seyxas expone más detalladamente el descubrimiento, explicando las circunstancias del viaje en que sucedió:

40 Seyxas y Lovera, 1688a, op. cit., fol. 65v.

41 McCarl, 2014b. Ghost journeys and phantom books: Francisco de Seyxas y Lovera's elusive library of pirates. Book History, 17, pp. 165-190.

42 Seyxas y Lovera, 1703b, op cit.

43 Idem.

44 Idem.
Siendo el año de 1676 Don Francisco de Seyxas y Lovera Capitan de fragata ligera [...] y el capitan Thomas Rupe de Nacion Ingles por haver ambos hecho viage años antes à la India Oriental, y à la China, acordaron de pasar con sus dos fragatas por la Region Austral Magallanica à las Malucas, y al Reyno de Sian à negociar, y haviendolos fomentado diferentes hombres Poderosos de Holanda y de Inglaterra para dicha Negociacion la lograron, y bolviendo para Europa accidentalmente descubrieron el dicho nuevo Pasage de la Mar del Sur al Mar del Norte, como se nota en este Mapa [... $]^{44}$.

Al final de aquella nota, Seyxas reitera su protagonismo del supuesto avance geográfico, presentándolo como la continuación -o la reivindicación- de una larga tradición española:

[P]ues asi como los Españoles fueron los primeros que la descubrieron [la Región Austral Magallánica], siendo Español D[o]n Francisco de Seyxas y Lovera tendrà la Gloria de haver sido hasta aòra el que ha reconocido mas hacia el Polo Antartico otro nuevo Pasage de un Mar à otro antes que otra Persona alguna de otra Nacion ${ }^{45}$.

La segunda edición de Theatro naval hidrographico ${ }^{46}$ refleja esta aparente apropiación posterior de Seyxas del descubrimiento. En la prínceps de 1688, Seyxas comenta las corrientes de los estrechos entre el Mar del Sur y el Mar del Norte, mencionando los de Le Maire, de Brouwer y de La Roche ${ }^{47}$. En la versión de 1704, el último de aquella serie se vuelve pasaje de Seyxas y también el que hé descubierto yo ${ }^{48}$. El autor efectúa el mismo cambio en el tratado al que acompaña el mapa de 1703, en que, como hemos notado, el séptimo discurso del "Libro quarto del virreynato del Tocuman" trata los

45 Idem

46 Seyxas y Lovera, 1704 [1688]. Theatro naval hidrographico de los fluxos, y refluxos y de las corrientes de los mares, estrechos, archipielagos, y pasages aquales del mundo. Pedro Gissey, París.

47 Seyxas y Lovera, 1688a, op. cit., fol. 65v.

48 Seyxas y Lovera, 1704 [1688], op. cit., p. 109. 
pasages del mayre[,] de Brovers, y del de Seyxas y $R u p e^{49}$, compartiendo el crédito en esa ocasión con su compañero de viaje.

Para mayor confusión, ya existía desde por lo menos 1688 una falta de claridad en cuanto a la fecha del supuesto descubrimiento del estrecho de La Roche. Aunque en Descripcion geographica (1690) y Piratas y contrabandistas (1693) el año es 1675, en la primera edición de Theatro naval hidrographico (1688a) y en el mapa de 1690, Seyxas indica que es 1678 , como en el mapa de 1703. Tal vez en aquellos dos casos, Seyxas señalara equivocadamente la fecha de la supuesta publicación del texto de La Roche -que él pone como 1678 en Descripcion geographica ${ }^{50}$ y no la del descubrimiento mismo.

El mapa de 1703 no solo se diferencia del otro en cuanto a la supuesta autoría del descubrimiento, sino también en la naturaleza de la tierra descubierta. Seyxas había representado la tierra que costeó La Roche en el mapa de 1690 como una sola isla, y sin ponerle nombre (Fig. 1). En el mapa de 1703, sin embargo, el autor denomina aquella misma tierra i[sla]s de la Roche (Fig. 6).
De los varios textos en que Seyxas escribe sobre el estrecho de La Roche, Descripcion geographica probablemente sea el único que influyera en el modo en que se representaban el estrecho de La Roche y la Tierra de Roche (no isla o islas de la Roche, como propone Seyxas en sus mapas) en la cartografía de la época. No es probable que los otros tuvieran resonancia en este sentido, pues Theatro naval hidrographico no narra el descubrimiento mismo, sino que solo comenta de forma breve las corrientes del Estrecho, y los demás no se imprimieron.

A pesar de ser el único texto en transmitir la historia del Estrecho, Descripcion geographica tuvo repercusiones a lo largo del siglo XVIII e incluso hasta el presente. Entre los muchos mapas de la época que recogen el supuesto hallazgo -aparentemente a partir de aquel texto- figuran los de Guillaume L'Isle ${ }^{51}$, Romeyn de Hooghe ${ }^{52}$, Herman Moll ${ }^{53}$, John Senex ${ }^{54}$, Louis Delarochette ${ }^{55}$ -que apunta que es muy dudoso-, Jean Baptiste Bourguignon d'Anville ${ }^{56}$ y Thomas Kitchin ${ }^{57}$. En los mismos años, el supuesto descubrimiento de La Roche mantiene una presencia en los repertorios

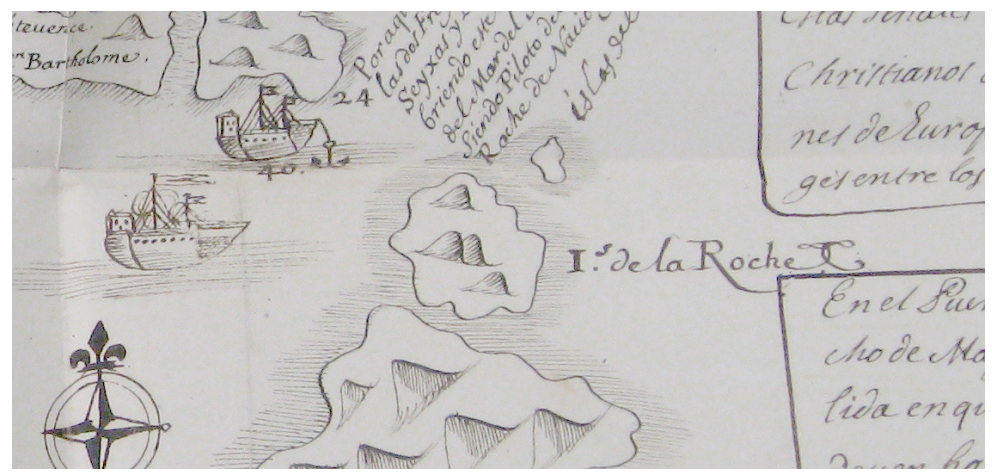

Fig. 6. Detalle del mapa de Seyxas y Lovera, 1703: las i[sla]s de la Roche. FR-MAE Centre des Archives diplomatiques de La Courneuve, Francia.

49 Seyxas y Lovera, 1703a, op. cit., fol. 8r-v.

50 Seyxas y Lovera, 1690, op. cit., fol. 27v.

51 L'Isle, h. 1705, L'Amerique Meridionale, Paris, chez l'auteur, David Rumsey Map Collection. http://www.davidrumsey. com/maps4425.html; 1716, op. cit.; 1752, America das Südliche nach der Zeichnung des Herrn Wilhelm Delisle in Verlag Joh. Justin Gebauers, Halle: bey Johann Justinus Gebauer, JCB Map Collection, John Carter Brown Library, https://jcb.lunaimaging.com/luna/servlet/s/ory2pi; h. 1759, op. cit.

52 Hooghe, 1710, L'Amerique Meridionale, Suivant les Nouvelles Observations de Messrs. de l'Academie Royale des Sciences, etc. Leiden: Chez Pierre van der Aa., JCB Map Collection, John Carter Brown Library, https://jcb. lunaimaging.com/luna/servlet/s/39z0sm.

53 Moll, 1720, op. cit.; h. 1736, op. cit.

54 Senex, h. 1755, op. cit.

55 Delarochette, h. 1771, South America from the latest discoveries, shewing the Spanish \& Portuguese settlements according to Mr. D'Anville by De Larochette, Printed for John Bowles, London, JCB Map Collection, John Carter Brown Library, https://jcb.lunaimaging.com/luna/servlet/s/7c072z.

56 D'Anville, 1772, op. cit.

57 Kitchin, 1784, A new map of the whole continent of America divided into North and South and West Indies, Printed for Robt. Sayer and John Bennett, London, JCB Map Collection, John Carter Brown Library. https://jcb. lunaimaging.com/luna/servlet/s/nbqc9d. 
y descripciones geográficas, también a partir de lo que cuenta Seyxas en Descripcion geographica. Figura, por ejemplo, en la Histoire naturelle, générale et particulière de Georges-Louis Leclerc Comte de Buffon y Louis Jean Marie Daubenton ${ }^{58}$, el Dizionario storico-geografico de Coleti $^{59}$ y el Diccionario geográfico-histórico de las Indias Occidentales de Alcedo ${ }^{60}$.

Descripcion geographica también fue la fuente principal -o exclusiva- de los historiadores $y$ otros que desde por lo menos finales del siglo XVIII han considerado el descubrimiento del estrecho de La Roche y la confusión geográfica que ha provocado. Entre ellos, destacan, en los siglos XVIII y XIX, Alexander Dalrymple ${ }^{61}$, James Cook $^{62}$, James Colnett ${ }^{63}$, James Burney ${ }^{64}$, Fabian Gottlieb von Bellingshausen ${ }^{65}$, y los editores del The Nautical Magazine ${ }^{66}$. En el siglo XX, trataron el tema Edwin Balch ${ }^{67}$, L. Harrison Matthews ${ }^{68}$, E. W. Hunter Christie ${ }^{69}$, Peter Gerhard ${ }^{70}$, J. C.

58 Buffon y Daubenton, 1749. Histoire naturelle, générale et particulière. Chez J. H. Schneider, Amsterdam, Tomo 1, p. 407; Buffon y Daubenton, 1792. Historia natural, general y particular. Trad. Joseph Clavijo y Faxardo, Imprenta de la viuda de Ibarra, Madrid, Segunda edición, Tomo 2, p. 135.

59 Coleti, 1771, op. cit., Tomo 2, p. 117; 1975 [1771], op. cit., Tomo 2, p. 333.

60 Alcedo, 1788, op. cit., Tomo 4, p. 435.

61 Dalrymple, 1775. A collection of voyages chiefly in the Southern Atlantick Ocean. Printed for the Author, London, pp. 4-7.

62 Cook, 1777. A voyage towards the South Pole, and round the world. Performed in His Majesty's ships the Resolution and Adventure, in the Years 1772, 1773, 1774, and 1775. Strahan, W. y Cadell, T., London, Tomo 2, pp. 207-221.

63 Colnett, 2012 [1798]. A voyage to the South Atlantic and round Cape Horn into the Pacific Ocean. Cambridge University Press, Cambridge, pp. 12-14.

64 Burney, 1813. A chronological history of the voyages and discoveries in the South Sea or Pacific Ocean. Part III, from the year 1620, to the year 1688. Luke Hansard and Sons, London, pp. 395-404.

65 Bellingshausen, 1945. The voyage of Captain Bellingshausen to the Antarctic Seas, 1819-1821. Tomo 1, Frank Debenham (Ed.), Printed for the Hakluyt Society, Works Issued by the Hakluyt Society, Segunda Serie, 91, London, pp. 76 y 83.

66 "Isla Grande, South Atlantic Ocean", 1835, The Nautical Magazine, enero, pp. 1-8.

67 Balch, 1902. Antarctica. Allen, Lane \& Scott, Philadelphia, p. 55.

68 Matthews, 1931. South Georgia: The British Empire's
Beaglehole ${ }^{71}$, Ernesto Fitte ${ }^{72}$, N. M. Wace ${ }^{73}$, Laurio Destefani $^{74}$, Robert Headland ${ }^{75}$ y Peter Bradley ${ }^{76}$, entre otros, y en el XXI, Richard J. Campbell ${ }^{77}$ y John Harrison ${ }^{78}$.

Algunos de los autores citan el texto de Seyxas directamente, $y$ otros recurren a él a través de los libros de Cook y de Burney. Varios incluso reproducen secciones enteras de Descripcion geographica traducidas al inglés. Burney, por su parte, cita de forma textual del español original, pues mientras no cuestiona la verdad de lo que Seyxas cuenta, afirma que el texto no se puede traducir debido a su carácter ambiguo: Seixas, to whom thanks are due for the information which he alone has preserved, may not be praised for clearness or precision (Seyxas, a quien debemos agradecer la información que solo él ha conservado, no puede ser celebrado por escribir ni con nitidez ni con precisión) ${ }^{79}$.

No se ha descartado la posibilidad de que hubiera algo cierto en lo que Seyxas cuenta, pero

subantarctic outpost. John Wright and Sons, Bristol, pp. 46-50 y p. 56

69 Christie, 1951. The Antarctic problem. An historical and political study. George Allen \& Unwin, London, pp. 41-46.

70 Gerhard, 1960. Pirates on the West Coast of New Spain, 1575-1742. A. H. Clark Co., Glendale, CA, pp. 143-144.

71 Beaglehole, 1961. The journals of Captain James Cook on his voyages of discovery: II. The voyage of the Resolution and Adventure, 1772-1775. Published for the Hakluyt Society at the University Press, Cambridge, p. 617, n. 2.

72 Fitte, 1968. La disputa con Gran Bretaña por las islas del Atlántico Sur. Emecé Editores, Buenos Aires, pp. 40-47.

73 Wace, 1969. The discovery, exploitation and settlement of the Tristan da Cunha Islands. Proceedings of the Royal Geographical Society of Australasia, South Australian Branch, 70, pp. 12-14.

74 Destefani, 1982. The Malvinas, the South Georgias and the South Sandwich Islands: The conflict with Britain. Edipress. Buenos Aires, pp. 111-112.

75 Headland, 1989. Chronological list of Antarctic expeditions and related historical events. Cambridge University Press, Cambridge, p. 65.

76 Bradley, 1989, op. cit., p. 101; 1999. British maritime enterprise in the New World: From the late fifteenth to the mid-eighteenth century. E. Mellen Press, Lewiston, NY, p. 443, n. 24.

77 Campbell, 2000 (Ed.). The discovery of the South Shetland Islands. The Hakluyt Society, London, p. 22.

78 Harrison, 2012. Forgotten footprints: Lost stories in the discovery of Antarctica. [Cardigan, Wales]: Parthian, pp. 18 y 432.

79 Burney, 1813, op. cit., p. 395 
tampoco se conocen pruebas documentales para apoyar su historia. El consenso parece ser que la tierra encontrada por La Roche -si el viaje y descubrimiento de verdad ocurrieron- debe ser la isla de Georgia del Sur, como sugieren los estudios de Mill $^{80}$, Matthews ${ }^{81}$, Christie ${ }^{82}$, Beaglehole ${ }^{83}$, Headland ${ }^{84}$, Campbell ${ }^{85}$ y Harrison ${ }^{86}$.

Partiendo, al parecer, de esta teoría, el nombre La Roche Strait se usó por muchos años para designar el actual Bird Sound, un estrecho que separa South Georgia de Bird Island, una isla pequeña en su extremo noroeste ${ }^{87}$. Matthews ${ }^{88}$ observa que, en realidad, aquel pasaje es demasiado estrecho para corresponder a la descripción que tenemos del descubrimiento de La Roche -a través de Seyxas-, y que La Roche debió de haber pasado más bien entre South Georgia y las formaciones denominadas las rocas Clerke, al sureste de la isla.

De todas formas, el supuesto descubrimiento sigue conmemorado en por lo menos dos topónimos actuales: el nombre de Roché Peak (una montaña en Bird Island ${ }^{89}$ ) y en el del Roché Glacier en el continente de Antártica. Del segundo, el Scientific Committee on Antarctic Research propone en su diccionario geográfico la siguiente etimología: Named after the British pioneer of Antarctica Anthony de la Roché who discovered the first land in the Antarctic region (Roché Island, present South Georgia) in 1675 (nombrado por el explorador pionero de la Antártida Antonio de la Roche, primer descubridor da la primera tierra en la región antártica -la isla de Roché, hoy en día la isla Georgia del Sur, en

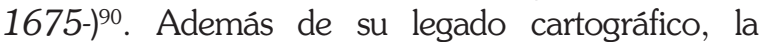

80 Mill, 1905. The siege of the South Pole. Frederick A. Stokes, New York, pp. 39 y 81.

81 Matthews, 1931, op. cit., pp. 48-50.

82 Christie, 1951, op. cit., p. 41 y pp. 43-44

83 Beaglehole, 1961, op. cit., p. 617, n. 2.

84 Headland, 1992 [1984]. The Island of South Georgia. Cambridge University Press, Cambridge, 1992, pp. 21-22.

85 Campbell, 2000 (Ed.), op. cit., p. 22.

86 Harrison, 2012, op. cit., pp. 18 y 432.

87 Holtedahl, 1929. On the geology and physiography of some Antarctic and sub-Antarctic islands. Jacob Dybwad, Oslo, pp. 59-60 y p. 70 .

88 Matthews, 1931, op. cit., pp. 48-50.

89 Antarctic Place-Names Committee, 1974 [1962]. Gazetteer of the British Antarctic Territory, South Georgia and the South Sandwich Islands. Her Majesty's Stationary Office, supuesta historia de La Roche sigue teniendo alguna relevancia dentro del contexto de la disputa territorial entre Argentina y la Gran Bretaña ${ }^{91}$.

\section{Las colonias inglesas}

El tercer aspecto que diferencia el mapa de Seyxas de casi todos los demás de la época es la representación de dos colonias inglesas en la Región Austral. La primera es una supuesta fortificación en Tierra del Fuego que, según el mapa, data de mediados del siglo XVII (Fig. 7). La segunda es una colonia en la costa pacífica, al norte del Estrecho, establecida supuestamente en 1675 (Fig. 8).

La idea de tales colonias corresponde a una preocupación generalizada sobre la posibilidad de una presencia inglesa en la Región Austral en los años posteriores al viaje de Narborough, suscitada en gran medida por aquella expedición. En dos artículos recientes María Ximena Urbina Carrasco $^{92}$ estudia la circulación de noticias -entre Chile, Lima, Londres y Madrid- que posibilitaron estas sospechas. A través de su investigación, Urbina desentraña una compleja historia protagonizada por una multitud de sujetos diversos: Narborough y sus hombres; Carlos Enriques Clerque, el instigador de aquel viaje; el conde de Molina, el embajador español en Londres; Juan Henríquez, gobernador de Chile; y varios informantes indígenas; entre otros.

Urbina $^{93}$ explica que la noción de posibles asentamientos europeos o mestizos en la región databa de finales del siglo XVI, cuando Pedro Sarmiento de Gamboa estableció dos poblaciones

London.

90 Scientific Committee on Antarctic Research. (2019). Composite Gazetteer of Antartica. https://data.aad.gov. au/aadc/gaz/scar.

91 Destefani, 1982, op. cit., pp. 111-112; Sörlin, 2013. Science, Geopolitics and Culture in the Polar Region. Routledge, London, p. 334.

92 Urbina, 2017. La expedición de John Narborough a Chile, 1670: Defensa de Valdivia, rumores de indios, informaciones de los prisioneros y la creencia en la ciudad de los Césares. Magallania, 45(2), pp. 11-36; 2016. La sospecha de ingleses en el extremo sur de Chile, 1669-1683: Actitudes imperiales y locales como consecuencia de la expedición de John Narborough. Magallania, 44(1), pp. 15-40.

93 Urbina, 2017, op. cit., pp. 29-30. 


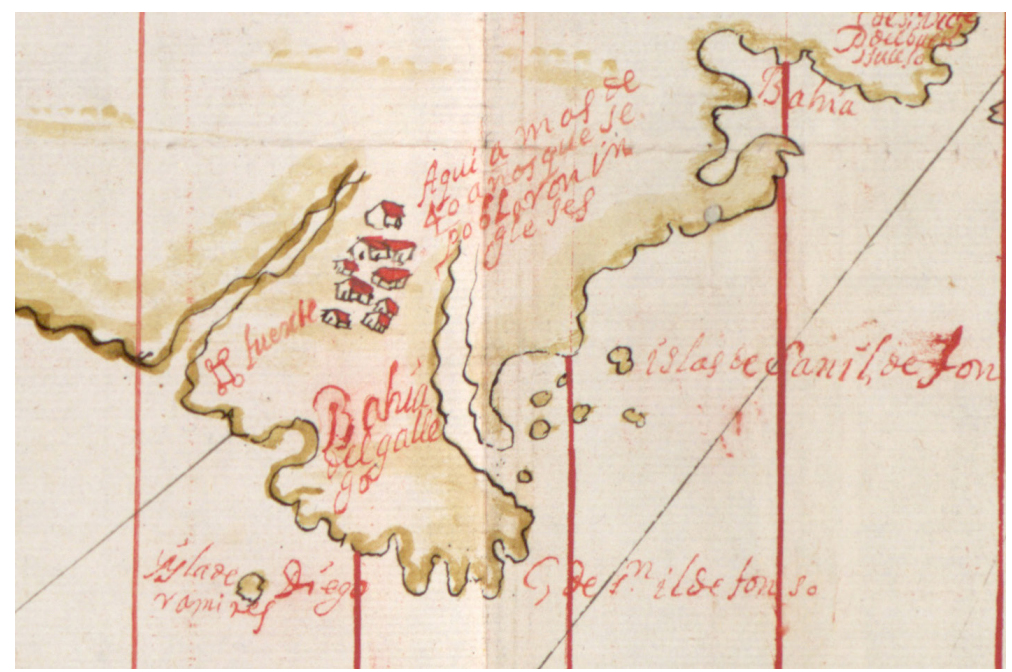

Fig. 7. Detalle del mapa de Seyxas y Lovera, 1690:

las fortificaciones inglesas en Tierra del Fuego.

Library of Congress, Geography and Map Division, Washington, D.C.

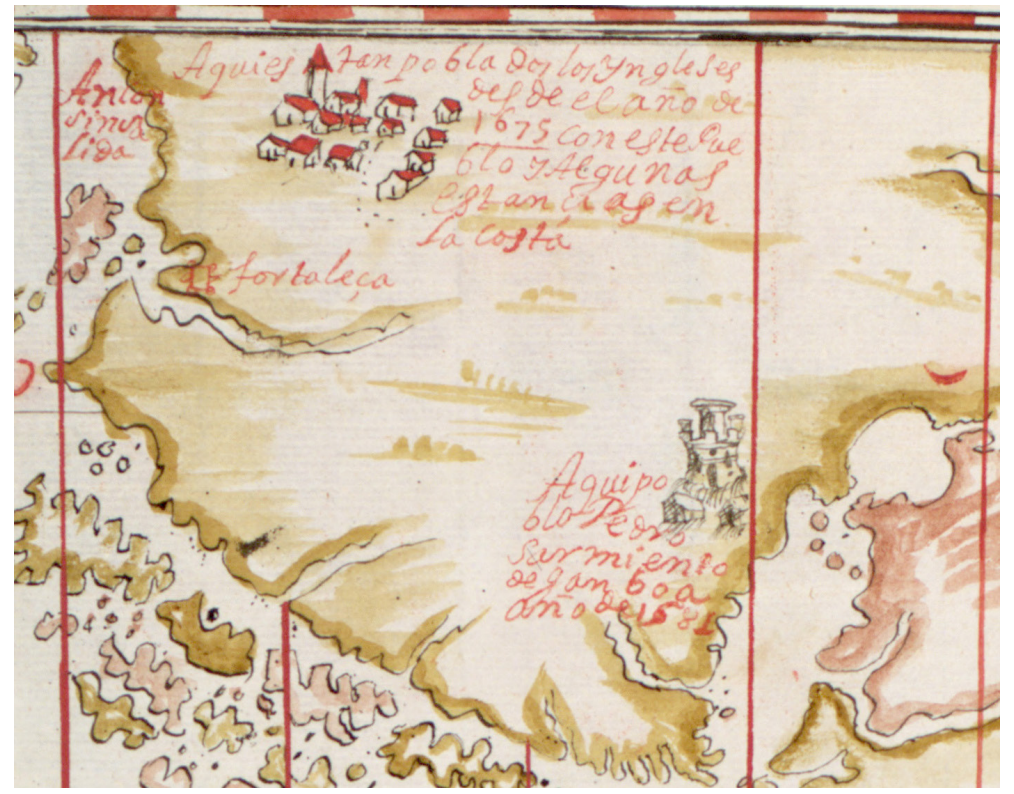

Fig. 8. Detalle del mapa de Seyxas y Lovera, 1690: la colonia inglesa al norte del Estrecho.

Library of Congress, Geography and Map Division, Washington, D.C.

fracasadas en el Estrecho después de que lo atravesó Francis Drake durante su viaje de circunnavegación. Según la leyenda que surgió, algunos sobrevivientes de aquellas colonias huyeron hacia el interior, donde se mezclaron con gente indígena y fundaron poblaciones europeas. Se trata de una adaptación del viejo mito de la Ciudad de los Césares, idea que tenía sus orígenes en la primera mitad de aquel siglo, cuando se desarrolló el concepto de una o varias ciudades escondidas y ricas en oro en la región patagónica. Como explica Urbina, todas aquellas sospechas cobraron nueva relevancia tras el viaje de Narborough y los rumores y miedos que 
generó. Como Juan Gil ${ }^{94}$, Urbina propone que el mito de la Ciudad de los Césares tal vez haya motivado el mismo viaje de Narborough, pues existen razones -como algunas de las afirmaciones de Enriques Clerque- para creer que el objetivo era, en realidad, encontrar aquella población para aprovecharse de su riqueza.

Como reacción al clima de recelo y la información que llegaba de varias fuentes, los españoles mandaron dos viajes de reconocimiento al Estrecho. Bartolomé Gallardo capitaneó el primero en 1674, y Antonio de Vea el segundo en $1675-1676^{95}$. Aunque no encontraron evidencias de poblaciones inglesas, la idea de su posible existencia persistía. Urbina incluye, por ejemplo, la reproducción de un mapa de Sudamérica ${ }^{96}$, ubicado en el Archivo General de Indias, que parece corresponder a una carta, también en el AGI, que Alonso de Pantoja, el procurador de la Compañía de Jesús en las Américas, mandó a la corte en 1680. Al este de una representación esquemática del extremo sur del continente, el mapa lleva la nota Poblacion de ingleses aqui en esta tierra del fuego, que refleja la afirmación en la carta de Pantoja que estaban poblados los ingleses en Tierra del Fuego ${ }^{97}$.

En Piratas y contrabandistas, Seyxas narra de forma pormenorizada una historia que parece corresponder a una de las colonias que representa en el mapa de 1690, la que propone que fue fundada al norte del Estrecho en 1675. Explica que un grupo de nobles regicidas -un milor y muchos caballeros, sus parientes, que vivian junto a Bristol- había huido de Inglaterra por miedo a la retribución de la monarquía Estuardo restaurada. Seyxas insinúa que la expedición fue inspirada en parte por el viaje de Enriques Clerque y Narborough a Chile, y en particular, al parecer, por una curiosa y particular relación con mapa de los puertos y ensenadas de aquella costa, desde Valdivia hasta el estrecho de Magallanes y de todo él que según el autor, publicaron Narborough y otros miembros de la tripulación al volver a Inglaterra ${ }^{98}$.

Según Seyxas, el viaje se armó con subterfugio, como otras expediciones que él

94 Gil, 1989. Mitos y utopías del descubrimiento. Alianza, Madrid, Tomo II, El Pacífico, pp. 293-305.

95 Urbina, 2016, op. cit., p. 29; 2017, op. cit., p. 25.

96 Urbina, 2016, op. cit., p. 34, fig. 4. narra en Piratas y contrabandistas. Primero, los organizadores liquidaron sus pertenencias y consiguieron los navíos de forma secreta:

[C]on todo secreto y maña trasfirieron el dominio de sus haciendas $y$ las vendieron, $y$ con todo el producto $y$ el dinero que tenían, 8 caballeros y el milor compraron 6 navios y en diferentes puertos de aquel reino los armaron con tanta maña y arte, consignados en distintas personas que pusieron por capitanes, que no supieron los unos de los otros.

Después los navíos partieron de forma clandestina, al parecer para despistar a sus posibles perseguidores, zarpando unos con pretexto de que iban a las islas de la Madera y de las Canarias y otros con el de que huian a las islas de Barlovento. Según Seyxas, se reunieron las seis embarcaciones en 1675 en Francia, en el puerto de San Martín de la isla de Ré, para allí terminar de alistarse y partir otra vez, el 12 de marzo de 1676. Seyxas apunta que iban acompañados de dos pilotos y seis individuos más, y que habían participado todos ellos, al parecer, en la expedición de Narborough. Del viaje entre Francia y Sudamérica solo comenta que pasaron por la isla de la Madera y por Cabo Verde, donde compraron esclavos: 120 negros y negras grandes y pequeños ${ }^{99}$.

Estos preparativos son el enfoque principal de la historia que Seyxas cuenta, sin ocuparse sino brevemente del establecimiento de las colonias y su estado actual. En cuanto al primero, explica que, después de pasar por el Estrecho, los ingleses erigieron la colonia en un lugar que parece corresponder a la actual provincia de Última Esperanza:

[E]ntrando por el Estrecho de Magallanes con toda felicidad y espacio, reconocieron bien sus costas y le pasaron, $y$ en el ancón sin salida demorando

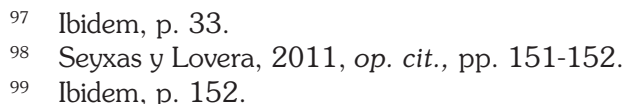


algunos días, pasaron a Cabo Corso, y en su costa, de 48 a poco menos de 50 grados, tendieron su población en 2 puertos con una fortaleza en cada uno, aunque no de mucha fuerza.

Los dos topónimos -cabo Corso y ancón sin salida- aparecen en su mapa de 1703, y el segundo en el de 1690, en que corresponde a la ubicación de la colonia inglesa ${ }^{100}$.

A propósito del estado actual de aquella población, Seyxas indica solo que había sobrevivido hasta el momento de escribir Piratas y contrabandistas, y que había tenido cierto éxito: [A]l amparo de ellas [las dos fortalezas] aquellos ingleses se van aumentando de tal manera que ya tienen muchas estancias, y dos lugares que cada dos años envían a Inglaterra corambre, lana y otras cosas que sacan de aquella costa ${ }^{101}$.

La narración de esta supuesta colonia responde a un trasfondo histórico real, pues al subir al trono, Charles II castigó a los que habían asesinado a su padre, confiscando sus bienes, matando a muchos y encarcelando a algunos ${ }^{102}$. Sin embargo, las historias que tratan la Restauración y los Estuardos no mencionan la huida de tal grupo de regicidas ${ }^{103}$. Aparte del trabajo de Urbina, las historias de la presencia inglesa en Sudamérica y en el Mar del Sur en aquella época no contemplan las supuestas colonias ${ }^{104}$.

Por lo menos hasta ahora, tampoco conocemos fuentes documentales sobre el caso. El mismo Seyxas concede que la información que proporciona le llegó por boca de otros marineros, no de textos escritos. Afirma que un libro sobre los mencionados asentamientos sí existía, pero que él no lo pudo revisar:

100 Ibidem, p. 153, n. 112 y n. 113.

101 Ibidem, pp. 152-153.

102 Coote, 2000. Royal survivor: A life of Charles II. St. Martin's Press, New York, p. 183.

103 Como por ejemplo, Glassey, 1997 (Ed.). The reigns of Charles II and James VII \& II,. St. Martin's Press, New York; Coote, 2000, op. cit.; Harris, 2005. Restoration: Charles II and his kingdoms, 1660-1685. Allen Lane, London; De Krey, 2007. Restoration and revolution in Britain: A political history of the era of Charles II and the
[A] unque hay escrito un tratado particular que se imprimió el año de 1683 en Bristol, no le he podido conseguir, sino solamente algunas noticias que algunos marineros y un capitán que hicieron este viaje me dieron en Londres el año de 1683, al cual capitán, que se llamaba Pedro Mauricio, le volví a ver en Madrid el año de 1686 [...] $]^{105}$.

Como en el caso de los mencionados textos de La Roche, y tantos otros que Seyxas menciona en Piratas y contrabandistas, no se ha encontrado ninguna prueba de la existencia del libro que el autor describe aquí106.

Mientras Seyxas en Piratas y contrabandistas así examina el contexto de una colonia que puede corresponder a la de 1675 en el mapa, en aquel texto no figura ninguna información que pueda responder a la otra, la que dice en el mapa que fue establecida en Tierra del Fuego más de 40 años antes de 1690. El autor tampoco registra ni aquella colonia ni la de 1675 en Descripcion geographica, que publicó en el mismo año en que fechó el mapa que estudiamos. La versión del mapa de 1703 complica más el asunto, pues en ella Seyxas omite toda mención de las supuestas colonias inglesas. En su lugar, representa al norte del Estrecho una serie de asentamientos diferentes, poblados por christianos españoles $y$ de otras naciones de Europa que estaban reducidos a salvages entre los indios gentiles ${ }^{107}$.

A pesar de la falta de evidencias documentales para apoyar las afirmaciones de Seyxas sobre las colonias inglesas, no es imposible que su historia merezca alguna consideración. El contexto detallado que este autor establece resulta difícil de descartar categóricamente, sobre todo

Glorious Revolution. Palgrave Macmillan, Basingstoke; Uglow, 2009. A Gambling Man: Charles II's Restoration Game. Farrar, Straus and Giroux, New York.

104 Gerhard, 1960, op. cit.; Bradley, 1989, op. cit.; Bradley, 1999, op. cit.; Williams, 1997. The great South Sea, English voyages and encounters, 1570-1750. Yale University Press, New Haven.

105 Seyxas y Lovera, 2011, op. cit., p. 153.

106 McCarl, 2014b, op. cit.

107 Seyxas y Lovera, 1703b, op. cit. 
por su especificidad y la forma en que describe la supuesta actividad económica de las colonias, que prefigura la forma en que la región magallánica sí sería explotada en el futuro por gente de afuera. Claro está, sin embargo, que las afirmaciones de Seyxas se desarrollan dentro de un contexto más amplio de leyendas sobre colonias en la región y de miedo generalizado tras el viaje de Narborough ${ }^{108}$. De todas formas -aunque resulte ser un producto de la imaginación de Seyxas o un elemento de la imaginación colectiva de los hombres de mar del momento- la historia por lo menos debe considerarse como parte del catálogo de mitos sobre la Patagonia, como los que recoge $\mathrm{Gil}^{109}$, y los discursos sobre la Patagonia como un lugar que se ha prestado a imaginaciones y visiones colonizadoras, como las que señala Fernanda Peñaloza ${ }^{110}$.

\section{CONCLUSIÓN: LOS TRES DISCURSOS}

Hemos considerado de forma breve tres de los aspectos más llamativos del mapa de Seyxas. Evidentemente, haría falta un estudio más comprehensivo para enfrentarnos a las dudas historiográficas y topográficas que provoca. Sin embargo, el objetivo aquí ha sido más modesto, tratándose de señalar una serie de posibles contextos discursivos en que podemos empezar a entender este mapa tan singular. Concluyo, por lo tanto, con un repaso de aquellos discursos, que son personales, políticos e imaginativos.

El mapa se encaja de forma clara en el programa de autopromoción de Seyxas. El acto de inscribirse en la cartografía con las Islas de Seyxas tal vez sea el ejemplo más obvio, pero producir el mapa y después entregárselo al rey en su Consejo de Indias también representan actos por los cuales el autor buscaba granjearse respeto y mejorar su estado. Desde dejar el mar y volverse escritor, Seyxas se esforzaba por reinventarse y lograr a través de sus experiencias marítimas alguna

108 Urbina, 2016, op. cit.; Urbina, 2017, op. cit.; McCarl, 2018a. The aftermath of the John Narborough expedition (1669-1671) in the viceroyalty of Peru. Colonial Latin American Review, 27, pp. 507-521.

109 Gil, 1989, op. cit.

110 Peñaloza, 2010. Introduction: Myths and realities. En Peñaloza, F., Wilson, J. y Canaparo, C. (Eds.). Patagonia: recompensa oficial. Se trata de un proceso que no termina con la adquisición de la alcaldía mayor de Tacuba, pues en cuanto llegó a la Nueva España entró de inmediato en conflicto con el virrey, y su estancia en aquella tierra consistió en una serie de encarcelamientos, tras los cuales Seyxas acabó exiliado en Versailles. Pasó sus últimos años en Francia tratando de reivindicarse y recobrar lo perdido, en términos de dinero y fama, a través de sus escritos ${ }^{111}$.

El mapa corresponde también a una de las agendas políticas más importantes de Seyxas, que consistía en llamar la atención de la Corona sobre la mala gestión de los terrenos de ultramar. Para dicho autor, tal situación frecuentemente se debía a la corrupción y la deslealtad de los miembros de la administración colonial, como también por la falta de conocimiento que había en la corte, e incluso en el mismo Consejo de Indias, sobre el mundo de ultramar ${ }^{112}$. En el caso de este mapa, Seyxas complementa el llamado que hizo en Descripcion geographica, y que haría después en Piratas y contrabandistas, sobre la urgencia de fortificar la Región Austral para prevenir el tránsito de los extranjeros por la zona, y además para que no la colonizaran. Tal vez la presencia de las supuestas colonias inglesas, y la versión tan específica que cuenta de su origen y actividades en Piratas y contrabandistas, sean un esfuerzo por crear una atmósfera de mayor urgencia.

Por último, debemos reconocer la posibilidad de que encontremos en el mapa de Seyxas el mismo discurso imaginativo que parece caracterizar otros de sus textos. Me refiero en particular a Piratas y contrabandistas, en que el autor cuenta varias historias que frisan lo inverosímil ${ }^{113}, \mathrm{y}$ al proemio a "Teatro real del comerzio de las monedas", en que representa su vida con evidentes rasgos de la novela picaresca -como la huerfanidad, los cambios de amo y de estado, y la lucha por la sobrevivencia a base de la astucia- y de la novela bizantina -como los viajes por mar, los ataques de

Myths and realities. Peter Lang, Oxford, pp. 1-25.

111 McCarl, 2011, op. cit., pp. xvii-xxii; McCarl, 2014b, op. cit., pp. 176-178; McCarl, 2018b, op. cit., pp. 117-121.

112 McCarl, 2011, op. cit., p. xlvi; McCarl, 2014a, op. cit.; McCarl, 2018b, op. cit., pp. 112-117.

113 McCarl, 2011, op. cit., p. xlv; McCarl, 2014b, op. cit., pp. 413-414. 
piratas y las identidades confundidas-. Además de las narraciones que son difíciles de creer, Seyxas teje una confusa red de supuestas fuentes escritas que, como el mencionado texto de La Roche y el otro sobre las colonias inglesas en el Estrecho, no se han podido identificar.

En fin, el mapa de Seyxas es, como lo ha denominado Martinic, tosco e imperfecto, y probablemente, con mucho de fabulado ${ }^{114}$. Sin embargo, con la publicación de Piratas y contrabandistas y los datos que hoy en día conocemos sobre el autor, su vida y sus ideas, podemos ver el mapa no solo como un capítulo curioso y aberrante en la historia de la cartografía magallánica. Al contrario, podemos entenderlo como un documento complejo en términos discursivos, que relaciona de forma íntima y visual la región magallánica con la vida y obra de uno de los escritores hispánicos más únicos de la segunda mitad del siglo XVII, y tal vez más generalmente con el imaginario colectivo de los hombres de mar de aquella época tan poco estudiada.

\section{BIBLIOGRAFÍA}

Isla Grande, South Atlantic Ocean. (1835). The Nautical Magazine, enero, 1-8.

Antarctic Place-Names Committee (1974 [1962]). Gazetteer of the British Antarctic Territory, South Georgia and the South Sandwich Islands. London: Her Majesty's Stationary Office.

Bagrow, L. (1964). History of Cartography. Cambridge: Harvard University Press.

Balch, E. S. (1902). Antarctica. Philadelphia: Allen, Lane \& Scott.

Beaglehole, J. C. (1961). The journals of Captain James Cook on his voyages of discovery: II. The voyage of the Resolution and Adventure, 1772-1775. Cambridge: Published for the Hakluyt Society at the University Press.

Bellingshausen, F. G. von (1945). The voyage of Captain Bellingshausen to the Antarctic Seas, 1819-1821. Tomo 1. Editado por Frank Debenham. London: Printed for the Hakluyt Society. Works Issued by the Hakluyt Society, Segunda Serie, 91.

Bradley, P. T. (1989). The lure of Peru: maritime intrusion into the South Sea, 1598-1701. New York: St.
Martin's Press.

Bradley, P. T. (1999). British maritime enterprise in the New World: From the late fifteenth to the mid-eighteenth century. Lewiston, NY: E. Mellen Press.

Burney, J. (1813). A chronological history of the voyages and discoveries in the South Sea or Pacific Ocean. Part III, from the year 1620, to the year 1688. London: Luke Hansard and Sons.

Campbell, R. J. (Ed.) (2000). The discovery of the South Shetland Islands. London: The Hakluyt Society.

Christie, E. W. Hunter. (1951). The Antarctic problem. An historical and political study. London: George Allen \& Unwin.

Coote, S. (2000). Royal survivor: A life of Charles II. New York: St. Martin's Press.

Cortesão, A., \& Teixeira da Mota, A. (1960). Portugaliae monumenta cartographica. 6 tomos. Lisboa: Comemorações do V Centenário da Morte do Infante D. Henrique.

De Krey, G. S. (2007). Restoration and revolution in Britain: A political history of the era of Charles II and the Glorious Revolution. Basingstoke: Palgrave Macmillan.

Destefani, L. (1982). The Malvinas, the South Georgias and the South Sandwich Islands: The conflict with Britain. Buenos Aires: Edipress.

Fernández de Navarrete, M. (1846). Disertación sobre la historia de la náutica y de las ciencias matemáticas. Madrid: Imprenta de la viuda de Calero.

Fitte, E. J. (1968). La disputa con Gran Bretaña por las islas del Atlántico Sur. Buenos Aires: Emecé Editores.

Gerhard, P. (1960). Pirates on the West Coast of New Spain, 1575-1742. Glendale, CA: A.H. Clark Co.

Gil, J. (1989). Mitos y utopías del descubrimiento. Tomo II, El Pacífico. Madrid: Alianza.

Glassey, L. K. J. (Ed.) (1997). The reigns of Charles II and James VII \& II. New York: St. Martin's Press.

Harris, T. (2005). Restoration: Charles II and his kingdoms, 1660-1685. London: Allen Lane.

Harrison, J. (2012). Forgotten footprints: Lost stories in the discovery of Antarctica. [Cardigan, Wales]: Parthian.

Headland, R. (1989). Chronological list of Antarctic expeditions and related historical events. Cambridge: Cambridge University Press.

Headland, R. (1992 [1984]). The Island of South Georgia. Cambridge: Cambridge University Press.

Holtedahl, O. (1929). On the geology and physiography of some Antarctic and sub-Antarctic islands. Oslo: 
Jacob Dybwad.

Library of Congress (1922). Report of the Librarian of Congress [...] for the fiscal year ending June 20, 1922. Washington: Government Printing Office.

Maggs, B. (1921). The voyages and discoveries of early travellers and missionaries. Part I, America. London: Maggs Bros.

Martinic, M. (1997). Rarezas cartográficas. I. Las cuatro versiones del mapa de Chile del padre Alonso de Ovalle. II. El curioso mapa de la región magallánica de Francisco de Seixas y Lovera (1690). Boletín de la Academia Chilena de la Historia, 107, 385-400.

Martinic, M. (1999). Cartografía magallánica 1523-1945. Punta Arenas: Ediciones de la Universidad de Magallanes.

Martinic, M. (2002). La curiosa primera representación de islas antárticas en un mapa del siglo XVII. En VI Encuentro de Historiadores Antárticos Iberoamericanos. Instituto Antártico Chileno, 57-62.

Martinic, M. (2005). De la Trapananda al Áysen: una mirada reflexiva sobre el acontecer de la Región de Aysén desde la prehistoria hasta nuestros dias. Santiago: Pehuén.

Matthews, L. H. (1931). South Georgia: The British Empire's subantarctic outpost. Bristol: John Wright and Sons.

McCarl, C. (2011). Introducción. Seyxas y Lovera, F. Piratas y contrabandistas de ambas Indias, y estado presente de ellas (1693). La Coruña: Fundación Pedro Barrié de la Maza, xi-liv.

McCarl, C. (2014a). Introducción. Seyxas y Lovera, F. Avisos a pretendientes para Indias. En Scholarly Editing: The Annual of the Association for Documentary Editing, 35. http://scholarlyediting.org/2014/editions/intro. avisos.html.

McCarl, C. (2014b). Ghost journeys and phantom books: Francisco de Seyxas y Lovera's elusive library of pirates. Book History, 17, 165-190.

McCarl, C. (2018a). The aftermath of the John Narborough expedition (1669-1671) in the viceroyalty of Peru. Colonial Latin American Review, 27, 507-521.

McCarl, C. (2018b). The "Taboas geraes" of João Teixeira Albernaz I as a mediated textual object. Quaerendo, 48(2), 106-126.

Medina, J. (Trad.) (1926). Relación del viaje de Hendrick Brouwer a Valdivia en 1643. En G. Feliú Cruz (Ed.). Opúsculos varios de J. T. Medina, Tomo 3. Santiago: Imprenta Universitaria.

Mill, H. R. (1905). The siege of the South Pole. New York: Frederick A. Stokes.
Narbrough, J. (2018). The voyage of Captain John Narbrough to the Strait of Magellan and the South Sea in His Majesty's ship Sweepstakes 1669-1671. Editado por R.J. Campbell, P.T. Bradley y J. Lorimer. London: Routledge. Works Issued by the Hakluyt Society Third Series $\mathrm{N}^{\circ} 33$

Peñaloza, F. (2010). Introduction: Myths and realities. En F. Peñaloza, J. Wilson \& C. Canaparo (Eds.), Patagonia: Myths and realities (pp. 1-25). Oxford: Peter Lang.

Putnam, R. (1985). Early maps and charts of the West Coast of North America: On the history of maps and sea charts, cartographers and publishers and on some periods of American history. Guernsey: Mercbook International.

Reitano, E. (2008). Carta de Francisco de Seyxas y Lovera en el Atlas Hidrográfico de João Teixeira de 1630. Anuario del Instituto de Historia Argentina, 8, 209-212.

Romero Magalhães, J. et al. (Coords.) (1997). Tesouros da cartografia portuguesa. Lisboa: Edições Inapa.

Scientific Committee on Antarctic Research. (2019). Composite Gazetteer of Antartica. https://data.aad.gov.au/ aadc/gaz/scar.

Seelstrang, A. (1885). Apuntes históricos sobre la Patagonia y la Tierra del Fuego. XX[.] Brouwer, Boletín del Instituto Geográfico Argentino, 6, 77-81.

Sörlin, S. (2013). Science, Geopolitics and Culture in the Polar Region. London: Routledge.

Uglow, J.S. (2009). A Gambling Man: Charles II's Restoration Game. New York: Farrar, Straus and Giroux.

Urbina, X. (2016). La sospecha de ingleses en el extremo sur de Chile, 1669-1683: Actitudes imperiales y locales como consecuencia de la expedición de John Narborough. Magallania, 44(1), 15-40.

Urbina, X. (2017). La expedición de John Narborough a Chile, 1670: Defensa de Valdivia, rumores de indios, informaciones de los prisioneros y la creencia en la ciudad de los Césares. Magallania, 45(2), 11-36.

Wace, N. M. (1969). The discovery, exploitation and settlement of the Tristan da Cunha Islands. Proceedings of the Royal Geographical Society of Australasia, South Australian Branch, 70, 11-40.

Williams, G. (1997). The great South Sea, English voyages and encounters, 1570-1750. New Haven: Yale University Press.

\section{FUENTES}

Alcedo, A. (1788). Diccionario geográfico-histórico de las Indias Occidentales. 5 tomos. Madrid: Imprenta de 
Manuel González.

Anónimo (1670a). A mapp of the streights of Magelan. British Library. Add. MS. 5414, artículo 29. Reproducido en Martinic, M. (1999), 59.

Anónimo (1670b). The Land of Patagonia [et cetera]. British Library. Maps K. Top. 124.84. Reproducido en Narbrough (2018) insertado entre pp. 368 y 369.

Anónimo (1671). Tabla del procedimiento del viaje de una fragata y un patache inglés al estrecho de Magallanes. Reproducido en Martinic, M. (1999), 60.

Anónimo (1690a). Mapa del estrecho de Magallanes y del nuevo de Mayre. Museo Naval, Madrid. Reproducido en Martinic, M. (1999), 65.

Anónimo (1690b). Mapa del estrecho de Magallanes y del nuevo de Mayre. Reproducido en Martinic, M. (1999), 66

Buffon, G. L. L., \& Daubenton, L. J. M. (1749). Histoire naturelle, générale et particulière. Tomo 1. Amsterdam: Chez J. H. Schneider.

Buffon, G. L. L., \& Daubenton, L. J. M. (1792). Historia natural, general y particular. Tomo 2. Traducción de Joseph Clavijo y Faxardo. Madrid: Imprenta de la viuda de Ibarra.

Cano y Olmedilla, J. (1799). Mapa geográfico de América meridional. London: Guillermo Faden. John Carter Brown Library, Map Collection. https://jcb. lunaimaging.com/luna/servlet/s/cl5fqc.

Coleti, G. D. (1975 [1771]). Diccionario histórico-geográfico de la América Meridional. Bogotá: Banco de la República. 2 tomos.

Coleti, G. D. (1771). Dizionario storico-geografico dell'America meridionale. 2 tomos. Venezia: Nella Stamperia Coleti.

Colnett, J. (2012 [1798]). A voyage to the South Atlantic and round Cape Horn into the Pacific Ocean. Cambridge: Cambridge University Press.

Cook, J. (1777). A voyage towards the South Pole, and round the world. Performed in His Majesty's ships the Resolution and Adventure, in the Years 1772, 1773, 1774, and 1775. Tomo 2. London: Strahan, W. y Cadell, T.

D'Anville, Jean Baptiste Bourguignon. (1772). A map of the whole continent of America divided into North and South and West Indies. London: Robt. Sayer. John Carter Brown Library, Map Collection. https://jcb. lunaimaging.com/luna/servlet/s/5vi83h

Dalrymple, A. (1775). A collection of voyages chiefly in the Southern Atlantick Ocean. London: Printed for the author.

Delarochette, L. (h. 1771). South America from the latest discoveries, shewing the Spanish \& Portuguese settlements according to $\mathrm{Mr}$. D'Anville by De Larochette. London: Printed for John Bowles. John Carter Brown Library, Map Collection. https://jcb. lunaimaging.com/luna/servlet/s/7c072z.

Hooghe, R. de. (1710). L'Amerique Meridionale, Suivant les Nouvelles Observations de Messrs. de l'Academie Royale des Sciences, etc. Leiden: Chez Pierre van der Aa. John Carter Brown Library, Map Collection. https://jcb.lunaimaging.com/luna/servlet/s/39z0sm.

Jaillot, A. H. (1696). L'Amerique meridionale divisée en ses principales parties. Paris: Chez H. Jaillot. John Carter Brown Library, Map Collection. https://jcb. lunaimaging.com/luna/servlet/s/9hyjpj.

Janssonius, J. (h. 1659). Tabula magellanica qua Tierrae del Fuego cum celeberrimis fretis a F. Magellano et I. Le Maire detectus novissima et accuratissima descriptio exhibetur. Amsterdam: Apud Joannem Janssonium. John Carter Brown Library, Map Collection. https:// jcb.lunaimaging.com/luna/servlet/s/noyfw8.

Kitchin, T. (1784). A new map of the whole continent of America divided into North and South and West Indies. London: Printed for Robt. Sayer and John Bennett. https://jcb.lunaimaging.com/luna/servlet/s/ nbqc9d.

Liebaux le fils. (1780). Carte du Paraguay du Chili du detroit de Magllan \&c. Paris: Chez Dezauche Successeur des Srs. De l'Isle et Buache. John Carter Brown Library, Map Collection. https://jcb.lunaimaging.com/luna/ servlet/s/27aez2.

L'Isle, G. de (h. 1705). L'Amerique Meridionale. Paris, chez l'auteur. David Rumsey Map Collection. http://www. davidrumsey.com/maps4425.html.

L'Isle, G. de (1716). Carte du Paraguay, du Chili, du Detroit de Magellan \&c. Amsterdam: Chez la veuve de Paul Marret. John Carter Brown Library, Map Collection. https://jcb.lunaimaging.com/luna/servlet/s/t62xm0.

L'Isle, G. de (1752). America das Südliche nach der Zeichnung des Herrn Wilhelm Delisle in Verlag Joh. Justin Gebauers. Halle: bey Johann Justinus Gebauer. John Carter Brown Library, Map Collection. https://jcb. lunaimaging.com/luna/servlet/s/ory2pi.

L'Isle, G. de (h. 1759). Typus Geographicus Chili Paraguay Freti Magellanici \&c. Nuremberg: Per Homanianos Heredes. John Carter Brown Library, Map Collection. https://jcb.lunaimaging.com/luna/servlet/s/hr7j4t.

Manneson, A. M. (1683). Detroit de Magellan, reproducido en Martinic, M. (1999), 63.

Moll, H. (1720). Map of South America including part of 
Central America, Solomon Islands, and a small part of Africa. London: Printed for H. Moll. John Carter Brown Library, Map Collection. https://jcb. lunaimaging.com/luna/servlet/s/ruola4.

Moll, H. (h. 1736). A map of Chili, Patagonia, La Plata and ye south part of Brasil. London: T. Bowles. David Rumsey Map Collection. https://www.davidrumsey. com/luna/servlet/detail/MSEY 8 1 3769 430105 ?id=1-1-3769-430105.

Montanus, A.. \& Ogilby, J. (1671). Tabula magellanica, reproducido en Martinic, M. (1999), 61.

Pruth, S. (1656). Le Paraguayr, le Chili, la Terre, et les Isles Magellanicques. Paris: Chez Pierre Mariette, rue Sainct Iacque à l'Esperance. John Carter Brown Library, Map Collection. https://jcb.lunaimaging.com/ luna/servlet/s/nc58qh.

Sanson, G. (1668). La Terre et les Isles Magellaniques, reproducido en Martinic, M. (1999), 57.

Sanson, N. (1680). South America divided into its principall parts. London: Sold by William Berry. John Carter Brown Library, Map Collection. https://jcb. lunaimaging.com/luna/servlet/s/x01n3l.

Senex, J. (h. 1755). South America corrected from the observation communicated to the Royal Society's [sic] of London \& Paris. London: Printed for $\mathrm{T}$. Bowles. John Carter Brown Library, Map Collection. https://jcb.lunaimaging.com/luna/servlet/s/54mghp.

Seyxas y Lovera, F. (1688a). Theatro naval hidrographico de los fluxos, y refluxos, y de las corrientes de los mares, estrechos, archipielagos, y passages aquales del mundo. Madrid: Antonio de Zafra.

Seyxas y Lovera, F. (1688b). Theatro real del comerzio de las monedas de la monarchia del Rey nuestro señor, con la mayor parte de todos los ymperios, reynos, y prouincias, de toda la mayor parte del universo, en que se manifiestan los considerables intereses que se llevan las naçiones por la falta de estimacion que las monedas esta monarcha deven tener. Real Biblioteca, Madrid. II/1800. El prólogo se ha transcrito en Seyxas y Lovera, F. (2011), 213-225.
Seyxas y Lovera, F. ["Seixas y Lovera"] (1690). Descripcion geographica, y derrotero de la region austral magallanica. Madrid: Antonio de Zafra.

Seyxas y Lovera, F. (1703a). Libro quarto del virreynato del Tocuman. Centre des Archives diplomatiques de La Courneuve (France), Mem. et Doc. 122 (Esp. 129), fols. 3r-183r. Tomo 4 de la serie La verdadera unión de las dos coronas de España y Francia.

Seyxas y Lovera, F. (1703b). Mapa manuscrito de la región magallánica. Centre des Archives diplomatiques de La Courneuve (France). Mem. et Doc. 122 (Esp. 129), fol. 183 .

Seyxas y Lovera, F. (1704 [1688]). Theatro naval hidrographico de los fluxos, y refluxos y de las corrientes de los mares, estrechos, archipielagos, y pasages aquales del mundo. París: Pedro Gissey.

Seyxas y Lovera, F. (2011). Piratas y contrabandistas de ambas Indias, y estado presente de ellas (1693). Editado por McCarl, C. La Coruña: Fundación Pedro Barrié de la Maza.

Teixeira Albernaz I, J. (1630). Taboas geraes da toda a navegaçã̃ divididas e emendadas por Dom Ieronimo de Attayde com todos os portos principaes das conquistas de Portugal. Delineadas por Ioão Teixeira Cosmographo de Sua Magestade. Anno de 1630. Library of Congress, Geography and Map Division, Washington. https://www. loc.gov/resource/g3200m.gct00052.

Thornton, J., J. Seller, William Fisher, James Atkinson, y John Colson. (h. 1670). A New Mapp of Magellan's Straights: Discovered by Capt. John Narbrough (Com[m]ander Then of His Majesty's Ship the Sweepstakes) As He Sayled Through the Sade Straights. London. John Carter Brown Library, Map Collection. https://jcb.lunaimaging.com/luna/ servlet/s/syjlwm.

Vea, A. de (1676). Exploración de las costas del extremo sur del continente, reproducido en Martinic, M. (1999), 62.

Witt, F. de (1675). Tractus Australior Americae Meridionalis, reproducido en Martinic, M. (1999), 61. 